Journal of Management and Bussines (JOMB)

Volume 1, Nomor 1, Juni 2019

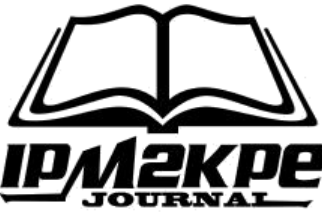

DOI : https://doi.org/10.31539/jomb.v1i1.626

\title{
ANALISIS TARGET LABA DALAM MEMAKSIMALKAN LABA UMKM ALVO ARCHERY KOTA SUKABUMI
}

\author{
Desti Karimah $^{1}$, Acep Samsudin ${ }^{2}$, Dicky Jhoansyah ${ }^{3}$ \\ Universitas Muhammadiyah Sukabumi ${ }^{1,2,3}$ \\ Email: destikarimah@gmail.com ${ }^{1}$
}

\begin{abstract}
ABSTRAK
Penelitian ini bertujuan untuk mengimplementasikan analisis target laba pada UKM Alvo Archery agar target laba yang telah direncanakan tercapai. Penelitian ini menggunakan metode observasi dan wawancara langsung pada UKM Alvo Archery untuk mendapatkan data yang diperlukan. Hasil Penelitian, UMKM Alvo Archery harus menjual produk: Horse bow sebanyak 108 unit, Batman sebanyak 131 unit, Brave sebanyak 95 unit, Elegan Dewasa sebanyak 159 unit, Elegant Kids sebanyak 396 unit, Street Fighter Dewasa sebanyak 193 unit, Street Fighter Kids sebanyak 173 unit, Elegant Long Bow sebanyak 143 unit, Mindful sebanyak 128 unit, Extreme sebanyak 157 unit, Fight Black sebanyak 128 unit, KZN 117 sebanyak 157 unit, Arrow Fiber Alvo sebanyak 1299 unit, Arrow Bambu Spons sebanyak 2320 unit, Arrow Ramin Spons sebanyak 2320 unit, Papan Target 50x50x5 sebanyak 773, Papan Target 100x100x5 sebanyak 286 unit. Simpulan, berdasarkan data-data diatas, maka UMKM Alvo Archery harus melakukan perencanaan laba terlebih dahulu agar laba yang diinginkan dapat tercapai. Dari hasil perhitungan diatas, UMKM Alvo Archery harus menjual produk nya sebanyak yang telah diperhitungkan diatas agar laba yang telah direncanakan tercapai dan mendapatkan laba yang maksimal.
\end{abstract}

Kata Kunci: Target Laba, Laba, UMKM

\section{ABSTRACT}

This study aims to implement a profit target analysis at the Alvo Archery UKM so that the planned profit target is achieved. This study uses the method of observation and direct interviews with UKM Alvo Archery to obtain the required data. Research Results, Alvo Archery MSMEs must sell products: 108 horse bow units, 131 units of Batman, 95 units of brave units, 159 units of Adult units, Elegant Kids with 396 units, Adult Street Fighter with 193 units, Street Fighter Kids with 173 units, 143 units of elegant long bow, 128 units of Mindful, 157 units of Extreme, 128 units of Fight Black, 157 units of KZN 117, 1299 Arrows of Alvo Fiber, 2320 units of Arrow Bambu Sponge, 2320 Arrow Ramin Sponge unit, Target Board 50x50x5 as many as 773, Target Board 100x100x5 as many as 286 units. Conclusion, based on the above data, then Alvo Archery MSMEs must make profit planning in advance so that the desired profit can be achieved. From the results of the above calculations, Alvo Archery MSMEs must sell their products as much as calculated above so that the planned profits are achieved and get the maximum profit.

Keywords: Target Profit, Profit, UMKM 


\section{PENDAHULUAN}

Perkembangan bisnis di Indonesia semakin hari semakin maju dan berkembang. Hal ini membuat persaingan semakin ketat dan menuntut agar perusahaan semakin berinovasi. Pada hakikatnya, setiap perusahaan memiliki tujuan dikemudian harinya supaya dapat berkembang lebih pesat. Perkembangan usaha pada dasarnya memiliki tujuan untuk memperoleh laba dan menjaga kontinuitas usahanya.Perkembangan dan kemajuan usaha akan membawa akibat bagi pembangunan perusahaan baik positif maupun negatif. Tujuan yang paling utama yang ingin dicapai oleh perusahaan adalah mendapatkan laba yang maksimal sesuai dengan yang telah direncanakan oleh perusahaan. Setiap perusahaan menginginkan agar tujuannya dalam meningkatkan laba dapat tercapai. Untuk mendukung pencapaian dari tujuan tersebut, perusahaan akan melakukan berbagai kegiatan dan inovasi bahkan sampai melakukan pelatihan bagi semua divisi perusahaan.

Pada umumnya, tujuan utama dari sebuah usaha adalah untuk memperoleh laba yang maksimal. Besar kecilnya laba yang diperoleh perusahaan dapat mengukur kinerja perusahaan itu sendiri dalam mengelola usahanya. Laba sebuah perusahaan dipengaruhi oleh beberapa faktor, yaitu biaya-biaya, harga jual produk dan volume penjualan. Ketiga faktor tersebut berkaitan antara satu dengan yang lainnya. Biaya-biaya menentukan harga jual, harga jual mempengaruhi volume penjualan, volume penjualan mempengaruhi biaya-biaya sehingga dalam proses perencanaan laba, manajemen menggunakan informasi tersebut untuk mempertimbangkan dampak dari perubahan biaya-biaya, harga jual serta volume penjualan terhadap laba bersih perusahaan. Berdasarkan hal itu, teknik perencanaan laba akan bermanfaat bagi manajemen apabila disertai dengan teknik analisa yang lain, diantaranya menggunakan analisis target laba.

Analisis target laba merupakan salah satu teknik analisis dalam mengukur maksimal laba yang didapatkan oleh perusahaan. Selain itu, analisis target laba dapat membantu pihak manajemen dalam membuat perencanaan laba. Analisis target laba juga membantu pihak manajemen dalam memahami prilaku biaya produk, serta laba operasi ketika terjadi tingkat output, harga jual, biaya tetap dan biaya variabel. Dengan demikian, pihak manajemen dapat menentukan volume penjualan yang dibutuhkan untuk mencapai target laba yang telah direncanakan dengan sumber daya yang dimiliki oleh perusahaan.Dewasa ini, pemerintah kota Sukabumi sedang gencar dalam 
mempromosikan dan mendukung masyarakat untuk membuka usaha mikro kecil menengah (UMKM). Seperti yang kita ketahui, UMKM memiliki peran penting dalam perekonomian dan salah satu faktor yang mendukung pertumbuhan ekonomi nasional terutama ekonomi daerah dan dapat mengurangi angka pengangguran. Maka dari itu, penulis memilih UMKM Alvo Archery sebagai objek penelitian.

UMKM Alvo Archery yang berdiri pada tanggal 16 Januari 2016 merupakan salah satu UMKM terbesar yang memproduksi alat-alat perlengkapan panahan di Indonesia. UMKM ini telah memiliki izin usaha dan penjualan peralatan olahraga panahan dengan nomor TDP: 10.05.5.47.00145. Untuk memudahkan konsumen dalam memesan produknya, UMKM ini tidak hanya memasarkan produknya secara offline tetapi telah melakukan penjualan secara online juga melalui media sosial, marketplace, bahkan sudah mempunyai website khusus dengan alamat www.alvoarchery.com. Selain itu, UMKM Alvo Archery ini sudah mempuyai reseller dan agen diberbagai kota seperti di Bandung, Bogor, Bekasi, Banten, Jambi, Batam, Sukabumi, Padang dan Solo.

Tidak hanya menjual produk saja, UMKM Alvo Archery juga membuka jasa pelatihan panahan untuk orang-orang yang berminat dengan olahraga ini yang bertempat di Toserba Selamat. Untuk hal ini, UMKM Alvo Archery telah mendapat izin melakukan kegiatan panahan dan tergabung dalam PERPANI (Persatuan Panahan Indonesia) dengan nomor SK PERPANI: SKP-16/PC.PERPANI KOTSI/VII/2018. Di kota Sukabumi, pada saat ini belum memiliki saingan UMKM yang memproduksi alatalat perlengkapan khusus panahan. Hal ini menjadi peluang besar untuk UMKM Alvo Archery.

Meskipun UMKM Alvo Archery tidak memiliki saingan dalam memproduksi alat-alat perlengkapan panahan di Indonesia, tentu saja masih ada masalah yang dihadapi oleh perusahaan. UMKM Alvo Archery memiliki kinerja yang baik tetapi perusahaan belum mengimplementasikan teori analisis target laba sehingga perusahaan sering mengalami kegagalan dalam mencapai target laba yang direncanakan. Oleh karena itu, dibutuhkan analisis target laba untuk membantu pihak manajemen dalam mencapai laba yang telah direncanakan dan untuk memaksimalkan laba yang didapat oleh perusahaan.

Menurut Samryn (2012), analisis target laba dalam aplikasi hubungan biaya volume dan laba pada dasarnya sama dengan analisis titik impas. Perbedaaannya hanya 
terletak pada jumlah laba yang diperhitungkan dalam formulanya. Dalam perhitungan titik impas target laba sama dengan nol, sementara dalam analisis target laba seperti yang dimaksudkan diatas jumlah laba diperhitungkan dalam formulanya disesuaikan dengan jumlah laba yang diinginkan, biasanya lebih dari nol.

Dari permasalahan diatas, maka UMKM Alvo Archery membutuhkan analisis target laba agar mencapai target laba yang telah direncanakan dan mendapatkan hasil yang maksimal.

\section{KAJIAN TEORI}

\section{Manajemen Keuangan}

Manajemen merupakan bagian paling penting dalam organisasi. Dalam suatu organisasi atau perusahaan, manajemen menjadi memiliki fungsi untuk mengatur atau mengelola segala aktivitas yang ada di perusahaan. Jika perusahaan memiliki pengelolaan yang baik maka perusahaan akan mudah dalam mencapai tujuannya. Sebagaimana yang telah dikemukakan oleh Andrew F. Sikula dalam Hasibuan (2016) bahwa manajemen berasal dari kata to manage yang artinya mengatur. Apa yang diatur, apa tujuannya diatur, mengapa harus diatur, siapa yang mengatur, dan bagaimana mengaturnya.

Fahmi (2014) menyatakan bahwa manajemen keuangan perusahaan merupakan penggabungan dari ilmu dan seni yang membahas, mengkaji dan menganalisis tentang bagaimana seorang manajer keuangan dengan mempergunakan seluruh sumber daya perusahaan untuk mencari dana, mengelola dana, dan membagi dana dengan tujuan mampu memberikan profit atau kemakmuran bagi para pemegang saham dan sustanability (keberlanjutan) usaha bagi perusahaan.

Utari, et.al (2014) mengemukakan fungsi manajemen keuangan (the management finance function) antara lain:

1. Sudut pandang organisasi (an organization view); fungsi manajemen keuangan menyajikan dumber dan penggunaan dana.

2. Hubungannya dengan Ilmu Ekonomi (relationship to economics); fungsi manajemen keuangan menyajikan penggunaan dana secara efisien dan output yang optimum. 
3. Hubungannya dengan Akuntansi (relationship to accounting); fungsi manajemen keuangan mennganalisis laporan akuntansi dari berbagai sudut pandang; likuiditas, solvabilitas, profitabilitas, dan aktivitas.

4. Aktivitas-aktivitas kunci manajemen keuangan (key activities of financial manager).

Kegiatan-kegiatan kunci manajemen keuangan meliputi; 1) menyajikan analisis keuangan dan perencanaan (performing financial analysis and planning); 2) membuat keputusan-keputusan investasi (making invesment decisions); 3) membuat kepuusankeputusan pembiayaan (making financing decisions); 4) peranan manajer keuangan dalam manajemen kualitas total (the financial manager's role in total quality management) ialah menyediakan informasi keuangan bagi manajemen untuk mengambil keputusan dalam hal perbaikan kualitas secara terus-menerus. Menurut Halim (2015) mengatakan bahwa tujuan yang ingin dicapai manajemen keuangan adalah memaksimalisasi kesejahteraan pemilik perusahaan atau memaksimalisasi nilai perusahaan.

\section{Biaya}

Menurut Sutrisno (2012) mengemukakan bahwa, biaya adalah pengorbanan ekonomi yang dikeluarkan oleh perusahaan untuk mendapatkan suatu barang, dana atau jasa. Penggolongan biaya menurut Sutrisno (2012) adalah sebagai berikut: 1) berdasarkan fungsi pokok perusahaan, a) mengacu pada fungsi pokok perusahaan tersebut, maka biaya juga dipisah mengikuti fungsi tersebut; b) biaya produksi. Biaya yang dikeluarkan untuk mengolah bahan baku menjadi produk selesai. Biaya ini dikeluarkan oleh departemen produksi yang terdiri dari biaya bahan baku, biaya tenaga kerja langsung dan biaya overhead pabrik; c) biaya non produksi. Biaya yang dikeluarkan oleh perusahaan selain biaya produksi. Biaya non produksi yang juga sering disebut sebagai biaya operasi ini terdiri dari biaya pemasaran, biaya administrasi dan umum, 2) berdasarkan Perilaku Biaya. Berdasarkan perilakunya yang dihubungkan dengan satuan kegiatan, maka biaya dapat dipisahkan ke dalam biaya variabel, biaya tetap, dan biaya semi variabel, yakni a) biaya variabel. Biaya yang jumlahnya berubahubah dan perubahannya proporsional dengan satuan kegiatan. Apabila satuan kegiatan ditingkatkan biaya variabel akan meningkat, dan bila satuan kegiatan menurun biaya 
variabel juga akan menurun secara proporsional; b) biaya tetap. Biaya yang jumlahnya tetap tidak terpengaruh oleh perubahan satuan kegiatan; c) biaya semi variabel. Biaya ini jumlahnya berubah-ubah tetapi perubahannya tidak proporsional dengan satuan kegiatan.

\section{Analisis Target Laba}

Menurut Samryn (2012) analisis target laba dalam aplikasi hubungan biaya volume dan laba pada dasarnya sama dengan analisis titik impas. Perbedaannya hanya terletak pada jumlah laba yang diperhitungkan dalam formulanya. Dalam perhitungan titik impas target laba sama dengan nol, sementara dalam analisis target laba seperti yang dimaksudkan di atas jumlah laba yang diperhitungkan dalam formulanya disesuaikan dengan jumlah laba yang diinginkan, biasanya lebih dari nol. Menurut Garrison et.al (2008:) analisis target laba dapat digunakan untuk menentukan volume penjualan yang dibutuhkan untuk mencapai target laba.Dalam bukunya, Samryn (2012:179) menggunakan formula untuk menghitung analisis target laba sebagai berikut:

$$
\begin{aligned}
& \text { Rasio Penjualan }=\text { Rasio Margin } \\
& \text { Kontribusi }+ \text { Biaya Tetap }+ \text { Laba }
\end{aligned}
$$

\section{METODE PENELITIAN}

Adapun metode penelitian yang penulis gunakan untuk menjawab masalah yang diteliti adalah metode penulisan deskriptif kuantitatif. Menurut Sugiyono (2013) menyatakan bahwa "penulisan deskriptif adalah penulisan yang dilakukan untuk mengetahui nilai variabel mandiri, baik satu variabel atau lebih (independen) tanpa membuat perbandingan atau menghubungkan antara variabel satu dengan variabel lain"

\section{HASIL PENELITIAN}

Tabel 1

Harga Jual Perunit

\begin{tabular}{ll}
\hline Nama Barang & Harga \\
\hline Horse Bow & Rp 800.000 \\
\hline Batman & Rp 850.000 \\
\hline Brave & Rp 1.200 .000 \\
\hline Elegant Dewasa & Rp 300.000 \\
\hline
\end{tabular}




\begin{tabular}{|c|c|}
\hline Elegant Kids & $\operatorname{Rp} 290.000$ \\
\hline Street Fighter Dewasa & $\operatorname{Rp} 700.000$ \\
\hline Street Fighter Kids & Rp 500.000 \\
\hline Elegant Long Bow & $\operatorname{Rp} 250.000$ \\
\hline Mindful & $\operatorname{Rp} 450.000$ \\
\hline Extreme & Rp 350.000 \\
\hline Fight Black & Rp 400.000 \\
\hline KZN 117 & Rp 300.000 \\
\hline Arrow Fiber Alvo & $\operatorname{Rp} 35.000$ \\
\hline Arrow Bambu Spons & $\operatorname{Rp} 20.000$ \\
\hline Arrow Ramin Spons & $\operatorname{Rp} 20.000$ \\
\hline Papan Target 50x50x5 & $\operatorname{Rp} 85.000$ \\
\hline Papan Target $100 \times 100 \times 5$ & Rp 175.000 \\
\hline
\end{tabular}

Tabel 2

Jumlah barang yang terjual bulan Desember 2018

\begin{tabular}{|c|c|}
\hline Nama Barang & Jumlah Terjual \\
\hline Horse Bow & 67 \\
\hline Batman & 48 \\
\hline Brave & 53 \\
\hline Elegant Dewasa & 51 \\
\hline Elegant Kids & 51 \\
\hline Street Fighter Dewasa & 43 \\
\hline Street Fighter Kids & 50 \\
\hline Elegant Long Bow & 67 \\
\hline Mindful & 68 \\
\hline Extreme & 58 \\
\hline Fight Black & 61 \\
\hline KZN 117 & 70 \\
\hline Arrow Fiber Alvo & 273 \\
\hline Arrow Bambu Spons & 315 \\
\hline Arrow Ramin Spons & 287 \\
\hline Papan Target 50x50x2 & 178 \\
\hline Papan Target 100x100x5 & 141 \\
\hline Total & 1.881 \\
\hline
\end{tabular}


Tabel 3

Biaya variabel Per Unit:

\begin{tabular}{|c|c|}
\hline Nama Barang & Biaya Variabel per Unit \\
\hline Horse Bow & $\operatorname{Rp} 498.000$ \\
\hline Batman & $\operatorname{Rp} 601.527$ \\
\hline Brave & Rp 857.000 \\
\hline Elegant Dewasa & $\operatorname{Rp} 95.266$ \\
\hline Elegant Kids & $\operatorname{Rp} 78.142$ \\
\hline Street Fighter Dewasa & $\operatorname{Rp} 256.958$ \\
\hline Street Fighter Kids & Rp 208.380 \\
\hline Elegant Long Bow & $\operatorname{Rp} 82.470$ \\
\hline Mindful & Rp 262.500 \\
\hline Extreme & Rp 124.200 \\
\hline Fight Black & Rp 147.500 \\
\hline KZN 117 & $\operatorname{Rp} 94.300$ \\
\hline Arrow Fiber Alvo & $\operatorname{Rp} 10.000$ \\
\hline Arrow Bambu Spons & $\operatorname{Rp} 6.000$ \\
\hline Arrow Ramin Spons & Rp 6.000 \\
\hline Papan Target 50x50x5 & $\operatorname{Rp} 43.000$ \\
\hline $\begin{array}{ll}\text { Papan } & \text { Target } \\
100 \times 100 \times 5 & \end{array}$ & $\operatorname{Rp} 89.200$ \\
\hline
\end{tabular}

Total biaya tetap bulan Desember $2018=$

Rp 847.839.504

Total biaya tetap per unit $=\operatorname{Rp} 4.710 .219$

Laba usaha yang diinginkan $=\mathrm{Rp} 416.000 .000$

Laba usaha yang diinginkan per unit $=$

Rp 27.777.777

\section{Rumus target penjualan dalam unit:}

Penjualan $=$ Biaya variabel per unit + Biaya tetap per unit + Laba

\section{Horse Bow}

$$
\begin{aligned}
& 800.000 \mathrm{x}=498.000+4.710 .219+27.777 .777 \\
& 800.000 \mathrm{x}-498.000 \mathrm{x}=4.710 .219+27.777 .777 \\
& 302.000 \mathrm{x}=32.487 .996 \\
& X \quad=32.487 .996 / 302.000
\end{aligned}
$$


Unit penjualan $(\mathrm{x}) \quad=108$ unit

\section{Batman}

$$
\begin{aligned}
& 850.000 x=601.527+4.710 .219+27.777 .777 \\
& 850.000 x-601.527 x=4.710 .219+27.777 .777 \\
& 248.473 x=32.487 .996 \\
& X \quad=32.487 .996 / 248.473
\end{aligned}
$$

Unit penjualan $(\mathrm{x}) \quad=131$ unit

\section{Brave}

$$
\begin{aligned}
& 1.200 .000 \mathrm{x}=857.000+4.710 .219+27.777 .777 \\
& 1.200 .000 \mathrm{x}-857.000 \mathrm{x}=4.710 .219+27.777 .777 \\
& 343.000 \mathrm{x}=32.487 .996 \\
& X \quad=32.487 .996 / 343.000
\end{aligned}
$$

Unit penjualan $(\mathrm{x}) \quad=95$ unit

\section{Elegant Dewasa}

$$
\begin{aligned}
& 300.000 x=95.266+4.710 .219+27.777 .777 \\
& 300.000 x-95.266 x=4.710 .219+27.777 .777 \\
& 204.734 x=32.487 .996 \\
& X \quad=32.487 .996 / 204.734 \\
& \text { Unit penjualan }(x) \quad=159 \text { unit }
\end{aligned}
$$

\section{Elegant Kids}

$$
\begin{aligned}
& 290.000 \mathrm{x}=208.280+4.710 .219+27.777 .777 \\
& 290.000 \mathrm{x}-208.000 \mathrm{x}=4.710 .219+27.777 .777 \\
& 82.000 \mathrm{x}=32.487 .996 \\
& \mathrm{X} \quad=32.487 .996 / 82.000
\end{aligned}
$$

Unit penjualan $(\mathrm{x}) \quad=396$ unit

\section{Elegant Long Bow}

$$
\begin{aligned}
& 250.000 \mathrm{x}=82.740+4.710 .219+27.777 .777 \\
& 250.000 \mathrm{x}-82.470 \mathrm{x}=4.710 .219+27.777 .777 \\
& \begin{array}{l}
167.530 \mathrm{x}=32.487 .996 \\
\mathrm{X}=32.487 .996 / 167.530
\end{array} \\
& \text { Unit penjualan }(\mathrm{x}) \quad=193 \text { unit }
\end{aligned}
$$




\section{Mindful}

$$
\begin{aligned}
& 450.000 x=262.500+4.710 .219+27.777 .777 \\
& 450.000 x-262.500 x=4.710 .219+27.777 .777 \\
& 187.500 x=32.487 .996 \\
& X \quad=32.487 .996 / 187.500 \\
& \text { Unit penjualan }(x)=173 \text { unit } \\
& \text { Extreme } \\
& 350.000 x=124.200+4.710 .219+27.777 .777 \\
& 350.000 x-124.200 x=4.710 .219+27.777 .777 \\
& 225.800 x=32.487 .996 \\
& X \quad=32.487 .996 / 225.800 \\
& \text { Unit penjualan }(x) \quad=143 \text { unit }
\end{aligned}
$$

\section{Extreme}

\section{Fight Black}

$$
\begin{aligned}
& 400.000 \mathrm{x}=147.500+4.710 .219+27.777 .777 \\
& 400.000 \mathrm{x}-147.500 \mathrm{x}=4.710 .219+27.777 .777 \\
& 252.500 \mathrm{x}=32.487 .996 \\
& \mathrm{X} \quad=32.487 .996 / 252.500 \\
& \text { Unit penjualan }(\mathrm{x}) \quad=128 \text { unit }
\end{aligned}
$$

\section{KZN 117}

$$
\begin{aligned}
& 300.000 \mathrm{x}=94.300+4.710 .219+27.777 .777 \\
& 300.000 \mathrm{x}-94.300 \mathrm{x}=4.710 .219+27.777 .777 \\
& 205.700 \mathrm{x}=32.487 .996 \\
& X \quad=32.487 .996 / 205.700
\end{aligned}
$$

Unit penjualan $(\mathrm{x}) \quad=157$ unit

\section{Arrow Fiber Alvo}

$$
\begin{aligned}
& 35.000 \mathrm{x}=10.000+4.710 .219+27.777 .777 \\
& 35.000 \mathrm{x}-10.000 \mathrm{x}=4.710 .219+27.777 .777 \\
& 25.000 \mathrm{x}=32.487 .996 \\
& X \quad=32.487 .996 / 25.000
\end{aligned}
$$

Unit penjualan $(\mathrm{x}) \quad=1299$ unit

\section{Arrow Bambu Spons}

$20.000 \mathrm{x}=6.000+4.710 .219+27.777 .777$ 


$$
\begin{aligned}
& 20.000 x-6.000 x \quad=4.710 .219+27.777 .777 \\
& 14.000 x \quad=32.487 .996 \\
& X \quad=32.487 .996 / 14.000
\end{aligned}
$$

Unit penjualan $(\mathrm{x}) \quad=2320$ unit

\section{Arrow Ramin Spons}

$$
\begin{aligned}
& 20.000 x=6.000+4.710 .219+27.777 .777 \\
& 20.000 x-6.000 x \quad=4.710 .219+27.777 .777 \\
& 14.000 x=32.487 .996 \\
& X \quad=32.487 .996 / 14.000
\end{aligned}
$$

Unit penjualan $(\mathrm{x}) \quad=2320$ unit

\section{Papan Target 50x50x5}

$$
\begin{aligned}
& 85.000 \mathrm{x}=43.000+4.710 .219+27.777 .777 \\
& 85.000 \mathrm{x}-43.000 \mathrm{x}=4.710 .219+27.777 .777 \\
& 42.000 \mathrm{x}=32.487 .996 \\
& X \quad=32.487 .996 / 42.000
\end{aligned}
$$

Unit penjualan $(\mathrm{x}) \quad=773$ unit

\section{Papan Target 100x100x5}

$$
\begin{aligned}
& 175.000 \mathrm{x}=61.700+4.710 .219+27.777 .777 \\
& 175.000 \mathrm{x}-61.700 \mathrm{x}=4.710 .219+27.777 .777 \\
& 113.300 \mathrm{x}=32.487 .996 \\
& \mathrm{X} \quad=32.487 .996 / 113.300
\end{aligned}
$$

Unit penjualan $(\mathrm{x}) \quad=286$ unit

\section{PEMBAHASAN}

Dari hasil perhitungan diatas, UMKM Alvo Archery harus menjual produk: Horse bow sebanyak 108 unit, Batman sebanyak 131 unit, Brave sebanyak 95 unit, Elegan Dewasa sebanyak 159 unit, Elegant Kids sebanyak 396 unit, Street Fighter Dewasa sebanyak 193 unit, Street Fighter Kids sebanyak 173 unit, Elegant Long Bow sebanyak 143 unit, Mindful sebanyak 128 unit, Extreme sebanyak 157 unit, Fight Black sebanyak 128 unit, KZN 117 sebanyak 157 unit, Arrow Fiber Alvo sebanyak 1299 unit, Arrow Bambu Spons sebanyak 2320 unit, Arrow Ramin Spons sebanyak 2320 unit, Papan Target 50x50x5 sebanyak 773, Papan Target 100x100x5 sebanyak 286 unit. 
UMKM Alvo Archery harus mampu menjual produk sejumlah yang telah diperhitungkan agar dapat mencapai target laba dengan hasil yang maksimal.

\section{SIMPULAN}

Berdasarkan data-data diatas, maka UMKM Alvo Archery harus melakukan perencanaan laba terlebih dahulu agar laba yang diinginkan dapat tercapai. Dari hasil perhitungan diatas, UMKM Alvo Archery harus menjual produk nya sebanyak yang telah diperhitungkan diatas agar laba yang telah direncanakan tercapai dan mendapatkan laba yang maksimal.

\section{DAFTAR PUSTAKA}

Abdul, Halim. (2015). Manajemen Keuangan Bisnis : Konsep dan Aplikasinya. Jakarta: Mitra Wacana Media

Dewi Utari, Ari Purwanti dan Darsono Prawironegoro. (2014). Manajemen Keuangan. Edisi Revisi. Jakarta: Mitra Wacana Media

Fahmi, Irham. (2014). Pengantar Manajemen Keuangan. Bandung: Alfabeta

Garrison, Noreen. (2008). Akuntansi Manajerial. Jilid 1. Edisi 11. Jakarta: Salemba Empat

Hasibuan, Malayu. S.P. (2016). Manajemen Dasar, Pengertian dan Masalah. Edisi Revisi. Jakarta: Bumi Aksara

Samryn, L.M. (2012). Akuntansi Manajemen. Edisi Revisi. Jakarta: Prenadamedia

Sugiyono, (2013), Metodologi Penelitian Kuantitatif, Kualitatif dan R\&D. Bandung: Alfabeta

Sutrisno. (2012). Manajemen Keuangan Teori, Konsep dan Aplikasi. Yogyakarta: Ekonisia 